\title{
Assessing poverty-alleviation outcomes of an enterprise-led approach to sanitation
}

\author{
Ted London ${ }^{1,2}$ and Heather Esper ${ }^{1}$ \\ ${ }^{1}$ William Davidson Institute, University of Michigan, Ann Arbor, Michigan. ${ }^{2}$ Ross School of Business, University of Michigan, \\ Ann Arbor, Michigan \\ Address for correspondence: Ted London, University of Michigan, William Davidson Institute, 724 E. University Ave., Wyly \\ Hall, Ann Arbor, Ml 48109. tlondon@umich.edu
}

Inadequate sanitation negatively affects the lives of billions of people in the base of the pyramid $(\mathrm{BoP})$ in the developing world, and has a particularly substantial impact on the well-being of millions of young children. Given the magnitude of the challenge and the limitations of existing approaches, enterprise-led approaches to providing public goods are generating growing interest. Emphasizing convergent innovation, enterprises targeting the BoP are presented as potentially sustainable and scalable interventions that generate positive poverty-alleviation effects. Yet our understanding of who is affected, and how, remains limited. To begin to address this gap, we apply a multidimensional framework to an urban-based, sanitation-oriented BoP enterprise, focusing on its poverty-alleviation effects on young children. Our analysis indicates that the enterprise's effects include changes in capability, economic, and relationship well-being and that these changes can be positive or negative. We also find that the impact varies depending on the role of the stakeholder in the business model and the age of the child. Our results contribute to a better understanding of how to assess the effectiveness of a sanitation intervention and how to evaluate the poverty-alleviation implications of an enterprise-led approach.

Keywords: enterprise-led approaches; poverty alleviation; sanitation; impact assessment; base of the pyramid

\section{Introduction}

Improving sanitation is one of the basic foundations for human development and a key component in improving well-being across the developing world. ${ }^{1,2}$ The combination of open defecation, poor hygiene, and lack of proper waste treatment can be deadly, particularly for young children in urban slums. $^{2}$ While both top-down and bottom-up interventions can generate positive health benefits, these approaches have yet to demonstrate that they can effectively address urban-based sanitation challenges. ${ }^{3}$ Relying on convergent innovation that combines top-down management and bottom-up ownership, enterprise-led approaches have gained increased attention as alternative poverty-alleviation strategies. ${ }^{4-8}$

Yet despite the growing interest in enterprise-led approaches to poverty alleviation, our understanding of their impact remains limited. Of particular concern is that an enterprise-led approach may have very different poverty-alleviation implications for different stakeholders in its business model. ${ }^{9}, 10$ This can be particularly relevant for enterprises that address a public good, such as sanitation, where both users and nonusers are affected by the intervention. ${ }^{2}$ To date, however, very little research has been done on the poverty-alleviation impacts of these enterprises across different stakeholders. ${ }^{9-12}$

In this study, we apply the base-of-the-pyramid impact assessment (BoP IA) framework to an enterprise providing sanitation services to urban slums in Kenya, with a focus on its poverty-alleviation impacts on children 5 years old and under. The BoP IA framework is particularly relevant for this type of assessment, as it accounts for changes across different dimensions of poverty and for variation across and within different groups. ${ }^{9}$ Our analysis shows that assessing changes across multiple dimensions of poverty, including capability, economics, and 
relationship well-being, improves our understanding of the effectiveness of a sanitation intervention. Furthermore, we find that examining how these poverty-alleviation impacts vary across different stakeholders provides important insights into the distribution of positive and negative outcomes and contributes to a better understanding of the overall poverty-alleviation outcomes of an enterprise-led approach.

\section{Inadequate sanitation and its impact on young children}

According to the World Health Organization (WHO), sanitation generally refers to the safe disposal of human waste as well as the maintenance of hygienic conditions. ${ }^{13}$ It is a public good with environmental and health benefits that extend beyond the individual user to the community at large., ${ }^{2,3}$ Most experts would agree that improving sanitation includes (1) reducing open defecation, (2) supporting better personal hygiene through more hygienic conditions and practices, and (3) enhancing water quality through safe collection, storage, treatment, and disposal or reuse of human waste through proper disposal or treatment of sewage. ${ }^{2}$

Inadequate sanitation can play a critical factor in explaining childhood health and cognitive performance. ${ }^{14}$ Providing adequate sanitation and hygiene education, for example, can reduce diarrhea, which is responsible for 1.5 million deaths annually. ${ }^{15}$ Improved sanitation alone can reduce this morbidity by $32 \% .{ }^{16}$ The majority of diarrhearelated deaths, approximately $90 \%$, are in children under 5 years of age in developing countries. ${ }^{17}$ For the children who survive, the impacts of poor sanitation and related nutritional deficits can include lower than average heights and diminished cognitive capabilities. ${ }^{14,18-22}$

Young children are particularly vulnerable to inadequate sanitation due to their greater exposure to hazards and their weak body defenses. ${ }^{23}$ Open defecation, for instance, contaminates the land where children play. ${ }^{2,24}$ When sanitation improvements are offered in urban settings, the results can be particularly beneficial. ${ }^{25}$ Studies, for instance, have found that urban-based sanitation improvements reduced child height deficit by $22-53 \%$, while similar ruralbased ones reduced child height deficit by $4-37 \% .^{26}$

Unhygienic toilet facilities and poor hygiene practices, such as limited opportunities for hand washing, also facilitate the spread of disease. Children's natural curiosity and tendency to touch many surfaces can increase the likelihood that they will come in contact with fecal matter in unclean sanitation facilities. ${ }^{23}$ Research shows that well-maintained toilets can decrease the number of deaths attributable to diarrhea by one-third, and hygiene education and proper hand washing can reduce diarrhea cases by $35-45 \% .{ }^{15-17}$ In addition to these direct effects, children are also impacted by the sanitation-related decisions and the hygiene behaviors of other members of the community. ${ }^{25}$ In particular, caregivers' exposure to poor sanitation increases their children's health risks. ${ }^{23}$

The method used to store and dispose of human waste also influences children's health outcomes. ${ }^{15}$ Untreated waste is often dumped into local water supplies. ${ }^{27,28}$ Contamination of drinking water also can occur through run-off from rain, transmission by flies and other animals, and human activity. ${ }^{29}$ Children can encounter this contaminated water through playing and drinking. ${ }^{23}$ Diarrhea morbidity is reduced by $6-25 \%$ with improvements in water supply. ${ }^{16}$

\section{Enterprise-led convergent innovation}

While the potential benefits are substantial, improved sanitation remains a major unmet goal for the global development community. The Millennium Development Goals (MDGs), the development community's officially established poverty reduction goals, include a target to increase global sanitation coverage to $75 \%$ by $2015 .{ }^{30}$ Despite much effort, this goal is unlikely to be met due to the size of the challenge. According to the United Nations, about 2.5 billion people still lack access to adequate sanitation. ${ }^{31}$

The impacts of poor sanitation are especially severe in urban areas as a result of increased density. Over the past three decades, much of the population growth in less-developed countries has occurred in urban areas. ${ }^{32}$ Sanitation infrastructure in these urban settings was not designed for this level of growth, and as a result, many urban-based sanitation facilities are already stressed beyond capacity. ${ }^{33}$ Furthermore, slums and other informal settings, often on the outskirts of these urban centers, typically do not have any centrally planned waste management infrastructure. 
Despite growing evidence on the impact of improved sanitation services as a public good, information on interventions that sustainably and effectively serve the urban poor remains scarce. ${ }^{3}$ Most solutions have emphasized top-down or bottom-up approaches that seek to maximize use of communal toilets. ${ }^{2,34}$ Both types of solutions, however, face challenges. In urban slums, top-down approaches, often based on government-led interventions, face cost, institutional, and coordination constraints. $^{2}$ These top-down approaches often struggle with obtaining the resources needed to install a comprehensive infrastructure. They can also face difficulties in managing these efforts across different regional and local bureaucracies, and they must overcome issues with regard to joint management and maintenance of any installed facilities. ${ }^{3}$

Community-based solutions such as communityled total sanitation (CLTS) emphasize bottomup ownership. Yet these approaches also face implementation challenges, particularly in urban settings. ${ }^{3,29,35}$ Over the past decade, CLTS's innovative approach has primarily been implemented in rural settings and has emphasized collective behavioral change. ${ }^{3}$ To achieve this, CLTS implementation relies on community consensus and strong local leaders. ${ }^{29,36}$ In urban settings, with a more transitory and heterogeneous population, coordination and community adherence becomes particularly challenging. ${ }^{3,34}$ Scaling the CLTS approach, especially in more densely populated environments, will also require more attention to addressing the issues of waste disposal and environmental health. ${ }^{3,29,35}$

Given these challenges, enterprise-led approaches relying on convergent innovation are presented as potentially viable alternatives. ${ }^{4,7}$ Enterprise-led convergent innovation is a key component in the BoP literature. ${ }^{37-39}$ The BoP, typically viewed as individuals earning less than $\$ 3000$ per year in purchasing power parity and who primarily live in the informal economy in the developing world, is estimated at four billion-more than half of the world's population. ${ }^{7,40} \mathrm{BoP}$ enterprises span sectors and size, and include ventures established by international and domestic companies, social entrepreneurs, and nonprofit organizations. ${ }^{41}$

In the BoP literature, enterprise-led approaches can embrace convergent innovation in two important ways. First, they seek to achieve economic viability while also generating positive poverty- alleviation outcomes. ${ }^{8,42}$ Similar to enterprises serving other markets, a central tenet of the BoP literature is the positive relationship between an enterprise's economic performance and its ability to create value for those it seeks to serve. ${ }^{40}$ The BoP literature adopts a poverty-based approach to addressing unmet needs. By reducing poverty, the enterprise creates value for its customers and can anticipate an economic return on that value creation.

Second, the BoP literature emphasizes the importance of viewing the BoP as active customers, producers, and entrepreneurs, rather than as passive recipients of donations and development programs. ${ }^{38}$ Successful enterprise development requires adopting a perspective of co-creation, which involves establishing an on-going dialogue with the BoP. ${ }^{42}$ In this way, the enterprise can combine business expertise from the top of the pyramid with consumer knowledge generated from the base. ${ }^{9}$

If a BoP enterprise scales, the number of people they reach and their purported positive impact on poverty grows. ${ }^{38}$ Yet our understanding of the poverty-alleviation impacts of these enterprises, including how they can vary across different stakeholders, remains limited. ${ }^{9,10}$

\section{Assessing enterprise-led poverty alleviation outcomes}

Poverty, which represents a lack of well-being, is multidimensional. ${ }^{9}$ The MDGs, for example, include different dimensions of poverty, such as health, education, and empowerment, among their targets for improvement. ${ }^{30}$ The first MDG, which is focused on eradicating extreme poverty, combines health and economic outcomes and incorporates income generation, employment creation, and reduction in undernourishment as targets.

The influence of poverty also varies across different stakeholders. The MDGs recognize differences in poverty's effects within families, including pregnant women and young children. ${ }^{30}$ Furthermore, even within a specific group such as young children, the impact of poverty can vary. Disease often more severely affects the youngest children, while older children are more likely to be exposed to disease due to their mobility and increased interactions with others.

A framework for understanding changes in different dimensions of poverty and how they vary within and across different groups has remained 


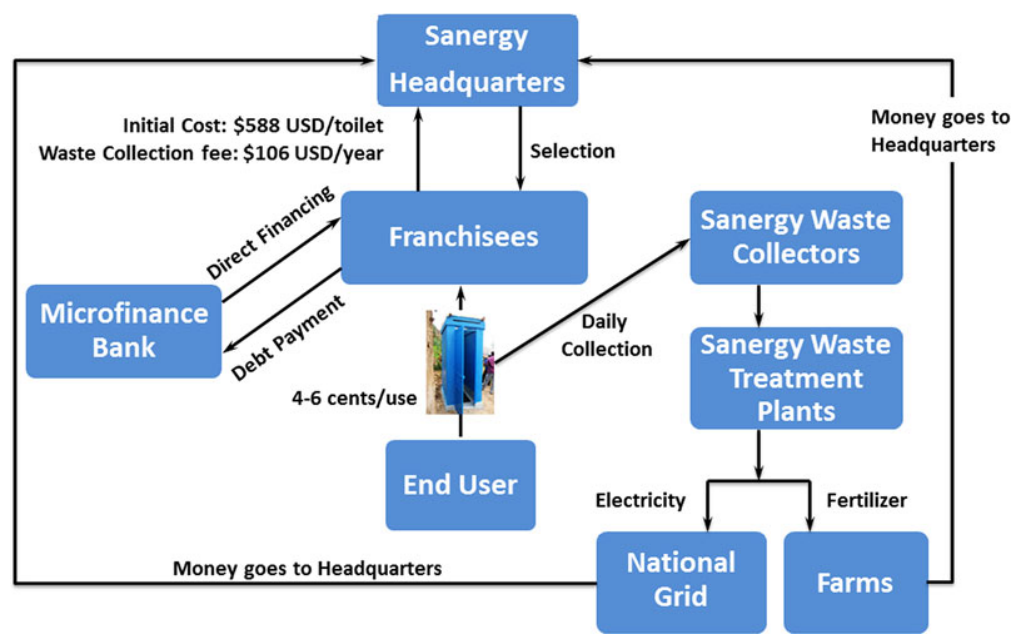

Figure 1. Sanergy's business model.

elusive. ${ }^{43-46}$ Recent work, however, has focused on reducing this gap. ${ }^{47}$ Leaders in the development and corporate communities have identified the BoP IA framework as a particularly useful tool for assessing an intervention's poverty-alleviation outcomes at the individual level. ${ }^{9,48,49}$

The BoP IA framework provides a theoretical basis for understanding how different dimensions of poverty affect individuals. The framework is designed to assess impacts across three areas of wellbeing: economics, capability, and relationships. ${ }^{9}$ Economic well-being captures control over financial resources for the purpose of consumption, production, investment, or exchange. This economic dimension includes changes in income and assets, and incorporates both short- and longterm impacts. ${ }^{50-52}$ The capability dimension encompasses an individual's agency, including knowledge and skills and physical and psychological health. ${ }^{9,12}$ Capability well-being examines opportunities and processes that enable or inhibit individual freedom. ${ }^{12}$ Relationship well-being includes resources that individuals can draw upon from their roles, status, and networks, as well as their surrounding environment. ${ }^{10,53,54}$ The relationship dimension moves beyond the individual by examining how interactions with others increases or reduces their isolation. ${ }^{9,54-56}$

\section{Sanergy: an enterprise serving the BoP}

In this study, we apply the BoP IA framework to a sanitation-oriented BoP enterprise focused on pro- viding a public good in an urban setting. Specifically, we examine changes in economic, capability, and relationship well-being across young children of different stakeholders affected by the enterprise's business model.

Sanergy, a for-profit (social) business launched in Kenya in 2009, has developed an integrated business model that addresses the challenges of open defecation, waste disposal, and poor hygiene practices (Fig. 1). Sanergy's business model is based on the convergence of economic and social performance goals. Sanergy's objective is to profitably build and scale sanitation infrastructure in urban slums while creating jobs and addressing urgent social needs associated with poor sanitation. The company executes its strategy by combining top-down central management with bottom-up ownership.

Serving urban slums in Nairobi, Sanergy developed an innovative communal pay-per-use sanitation solution in the form of a modular sanitation facility called Fresh Life Toilets (FLTs). The FLTs' compact size facilitates placement in high-density areas (Fig. 2). By using a franchising model, Sanergy can implement a set of standard operating procedures that are required across all the FLTs. This enables Sanergy to consistently manage the cleanliness of each FLT, ensure that franchisees are actively encouraging good hygiene practices, and oversee collection and disposal of waste.

To achieve economies of scale, Sanergy targets high-density urban areas, with an initial focus on Viwandani and Kwa Reuben in Nairobi's Mukuru 


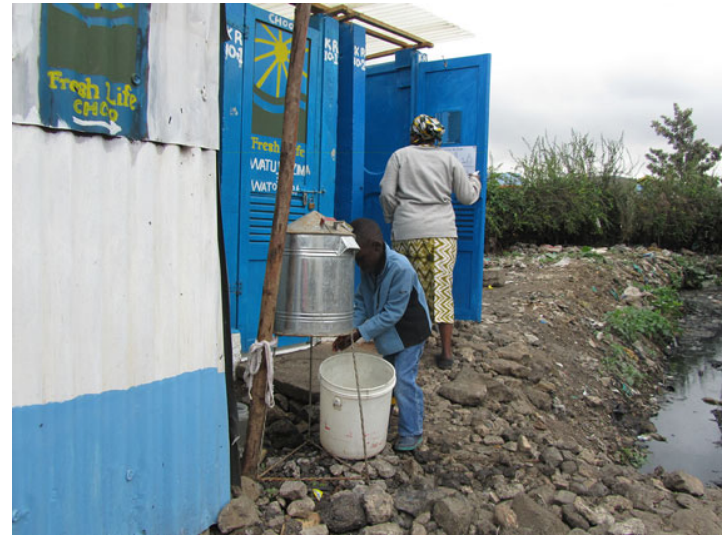

Figure 2. Image of Sanergy toilet with child washing hands in Mukuru slum.

slum. Mukuru, one of the poorest urban areas in Africa, has a population of over 250,000 and limited physical infrastructure. Human and other waste, such as from existing commercial toilets, is often dumped into the Ngong River, which passes through the slum (Fig. 3). ${ }^{57}$

Most Mukuru residents do not have bathrooms in their home. If they wish to use one of the few existing commercial options, Mukuru residents pay the equivalent of about U.S. \$0.03-0.06. These commercial toilets typically are a structure surrounding a hole in the ground with plastic sheeting. Such facilities are generally not well-maintained and do not include hand-washing stations. Many residents are unable or do not wish to pay for the use of these toilets. A popular alternative are "flying toilets"plastic bags that a person defecates in and then throws onto rooftops or into the street. Hanging latrines, another commonly used option, deposit untreated excreta directly into open water bodies.

Before opening their FLT to the public, franchisees receive training from Sanergy on how to operate the FLT, including strong reinforcement of the importance of all customers washing their hands after each use. Each FLT is stocked with toilet paper, soap, water, and a hand-washing station (Fig. 2).

The cost of an FLT is 50,000 Kenyan shillings (KES) (U.S. \$588), with financing facilitated through local microfinance organizations. This price includes waste removal for the first year, after which franchisees pay an annual fee of approximately 9000 KES (U.S. \$106). Sanergy franchisees charge 3-5 KES (about U.S. \$0.04-0.06) per use, which includes toilet paper and hand washing. As part of their franchise agreement, the FLT owners are expected to remind all of their customers to practice good sanitary hygiene, including washing hands with soap after toilet use. With each communal toilet averaging over 50 uses per day, the daily income from an FLT is between 150 and 250 KES (U.S. \$1.75-3.00). The capacity of each toilet is approximately 120 uses per day.

FLTs separate urine and feces into different containers to facilitate collection and use of the waste (Fig. 4). Each day, a team of Sanergy employees collect the containers with waste (both solid and liquid) and replace them with clean ones at each FLT. At the time of collection, the Sanergy employees also clean each toilet, and franchisees are expected to maintain Sanergy standards for quality and cleanliness between cleanings. The collected waste is then taken to Sanergy's central processing facility (Fig. 5). At this facility, the human waste is converted into biogas through an industrial-scale anaerobic digestion process. $^{a}$

As of May 2013, Sanergy had 179 communal FLTs serving about 8000 people. With 10 million people residing in Kenya's slums, Sanergy projects its BoP market potential as U.S. $\$ 72$ million per year in Kenya. ${ }^{58}$ Some $35 \%$ of its potential customers are children.

\section{Assessing Sanergy's impacts}

This study utilized a qualitative research methodology. We focused on developing and evaluating an in-depth case study, an effective approach when the goal is to understand the dynamics of multiple BoP stakeholders within a field setting. ${ }^{59,60}$ We used rigorous, established research strategies in our data collection and analysis. ${ }^{59,61}$ Our data collection focused on developing a rich and holistic understanding of Sanergy's impact on children, and included

${ }^{a}$ The biogas can then be combusted to generate electricity and sold to the national grid. The remaining product from the biogas generation can be processed into high-quality organic fertilizer and sold to commercial farms and smallhold farmers. To date, Sanergy has implemented the franchising model for FLTs, the daily waste collection, and the anaerobic digestion process. The electricity generation component is still under development. As such, our analysis focuses on the sanitation implications of Sanergy's model. 


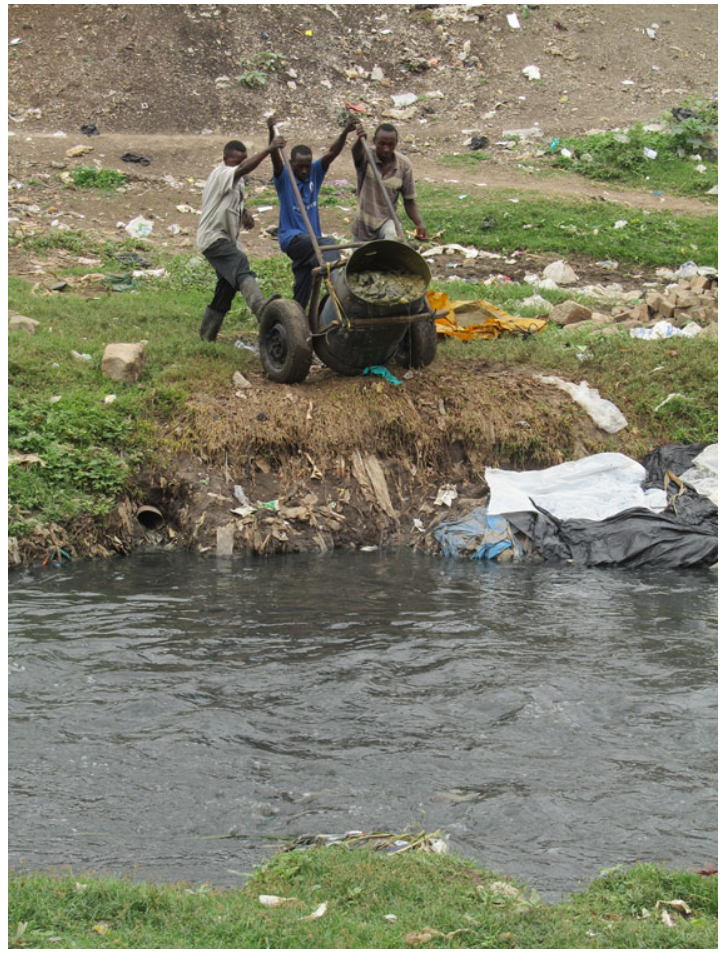

Figure 3. Image of waste from commercial toilet being dumped into Ngong River.

data in the form of documents, interviews, photographs, and observations. Our data analysis emphasized careful coding, detailed cross-group analysis, and triangulation across data sources to confirm findings.

Our investigation of Sanergy began before we entered the field. We first collected and analyzed secondary information about sanitation impacts on young children, including those related to open defecation, contamination of drinking water, and hygiene practices. We then carefully analyzed Sanergy's business model, including reviewing existing secondary information and discussions with the venture's founders. These rich sources of information provided key insights into potential impacts. Next, we developed an interview protocol that included a series of open-ended questions and followup probes to assess these potential impacts across different BoP stakeholder groups. Each stakeholder was asked a standard set of questions. We probed deeper into specific aspects of impact based on the respondent's answers to our questions. Specifically, we sought to assess how children 5 years of age and under are affected across three areas of well-being: economics, capability, and relationships. ${ }^{9}$ The interview protocol was designed to explore both the direct impacts of Sanergy's FLTs on these children and the impacts that occur on these children through their caregivers and other community members.

Then, in June 2012, we engaged in a robust process of field-data collection. We began by conducting detailed in-person interviews with key members of the company's management and operations team. We followed this with interviews of 20 stakeholders living in Mukuru. These respondents were selected to represent three key groups of BoP stakeholders, including franchisees, customers, and nonusers. Franchisees were defined as individuals who have purchased and operate at least one FLT. Customers were defined as individuals who pay to use Sanergy's FLTs. Nonusers were defined as community members who do not use Sanergy's FLTs. As sanitation provision is a public good, this study design does not allow for a control group within the same local community. Even the nonusers may receive some benefits from a cleaner physical environment. ${ }^{23,24}$ That said, nonusers are as close to a control group as possible within the same community Sanergy operates, in that the intervention's impact on them was relatively modest. To gain a more holistic picture of Sanergy's impact, we also interviewed locally based partners such as schools, clinics, governmental agencies, and nongovernmental organizations.

To explore the impacts of Sanergy's intervention, we employed several strategies in our interview protocol. ${ }^{b}$ We asked questions that focused on comparing the current well-being of their children to their status before Sanergy. To ensure completeness, in our follow-up probes, we asked respondents to reflect on how Sanergy's intervention had affected their children across different dimensions of well-being. We also probed into why they felt these changes were due to Sanergy. Furthermore, we encouraged our respondents to consider both positive and negative impacts on their children's well-being. We then asked the respondents to compare the wellbeing of their children to others in the community. For example, we asked customers to compare their child to those of nonusers. We assessed our collected

${ }^{b}$ The study was reviewed by our Institutional Review Board and determined to be exempt. 


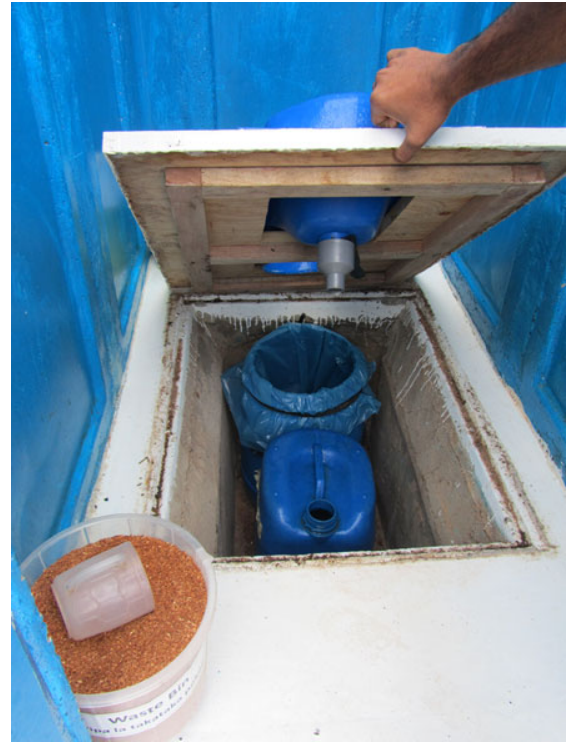

Figure 4. Image of inside of Sanergy toilet showing the separate containers.

data on an ongoing basis. This allowed us to recognize emerging patterns and identify any sources of variation during data collection. ${ }^{59,61}$ The latter also provided the opportunity to probe more deeply into key impacts until saturation, when additional data collection did not yield new insights. ${ }^{61}$ All the interviews were recorded.

We then developed detailed summaries for each interview. ${ }^{59}$ For each interview, we coded identified impacts based on type of well-being. ${ }^{61}$ Analysis of the coding resulted in a systematic process of grouping the raw data within our standardized framework, the BoP IA framework. We then conducted a within-group analysis to develop a summary of impacts for each stakeholder group. ${ }^{59,60}$ Next, we conducted cross-group comparisons, which enabled us to develop an understanding of relative changes in wellbeing. ${ }^{59,61}$ These results are presented in Table 1. Together these data provided a rich assessment of the impact of Sanergy's business model on children 5 years old and younger in the local community.

\section{Findings}

A child's bathroom use evolves by age. In Mukuru, through about age $2 \frac{1}{2}$ years, children use cloth diapers. Diaper waste is often disposed of by placing it in a paper bag and throwing it into a trash site, or discarding it as a flying toilet. From age $2 \frac{1}{2}$ to 3 years, the child is toilet trained using portable plastic toilets in the home, and the waste is disposed of in a similar manner. Caregivers begin to take children to a toilet facility when they reach age three, although many still defecate in the open or use flying toilets. The younger the child, the more socially acceptable it is for them to defecate in public.

Furthermore, our literature review indicated that children's exposure to fecal matter and the resulting outcomes differ by age. Older children, including those 3-5 years old, are more mobile and therefore are exposed to additional hazards and face increased risk of infection. ${ }^{23}$ Younger children, including those $0-3$ years old, are often kept close to home and interact with less people. However, younger children are also more vulnerable to disease transmission, have less understanding of potentially risky behaviors, and are less likely to adopt good hygiene practices such as washing their hands. ${ }^{23}$

Given this, we explored the poverty-alleviation impacts of Sanergy on two groups of children in Mukuru: those from ages $0-3$ and those from ages 3-5 years. We examined the impact on these two groups of children across three different roles their families can play in Sanergy's business model: franchisees, customers, and nonusers. For the children in each role, we evaluated how Sanergy's business model positively and negatively affects their economic, capability, and relationship well-being. Table 1 presents a summary of how the impacts on children varied by stakeholder role, child age, and type of well-being (see online supplementary material for additional data).

\section{Capability well-being}

As expected, our findings indicate that an important impact of Sanergy's business model is on the health of children 5 years old and younger. Our results also show that this impact varies across both age of the children and the stakeholder (caregiver) role in the business model. The impact of Sanergy's activities on the health of children can vary depending on whether the children are in the $0-3$ or $3-5$ year age group. These impacts also vary depending on whether these are children of franchisees, customers, or nonusers.

Children across all three BoP stakeholder groups can benefit from greater use of Sanergy's FLTs in the community. Sanergy's FLTs encourage more people to use a commercial toilet more often, resulting 


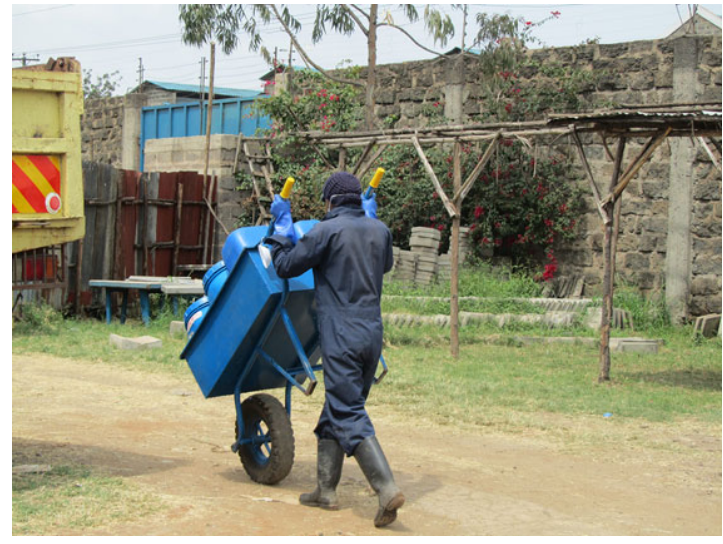

Figure 5. Image of Sanergy's waste management worker carrying waste out of the community.

in less open defecation. With a decline in the frequency of using flying toilets and of defecating and urinating on the ground, the local environment becomes cleaner. In discussing changes in the environment, a franchisee explained:

Before you won't go 10 meters without seeing a lot of [human] waste but now you can't see it. Even the air is not smelling. The village was smelling bad too, but now it is alright. (Franchisee 6)

\section{Similarly, a customer noted:}

The area has become more clean than it was before. Some of the people were putting the [human] waste in the papers and throwing on the rooftops. The diseases that were more affecting the children right now, they have gone down and have reduced, and more children are not getting sick as they were before. (Customer 3)

Our results showed that the quality of the land surrounding the FLTs displayed the most improvements. As FLTs are mainly located near the franchisee's home, children of franchisees gain the greatest benefits from these improvements in the physical environment. Franchisees, as part of their agreement with Sanergy, are expected to regularly sweep the area and keep it and any drainage near their FLT as clean as possible. As two different franchisees indicated:

There was many, many sicknesses like diarrhea. Now I think it has gotten reduced now.
Because there is not any waste around here now. The place around here now is very clean. (Franchisee 1)

They [my kids] were happy because the place would now become clean... For them bringing the Fresh Life toilet here, making the place so clean... There are no flies going to the children. I have noticed that. I am happy because I know my kids are going to be clean. (Franchisee 2)

The youngest children, those in the $0-3$ age group, can benefit the most from this cleaner environment. Children in this age group are more likely to crawl on the ground and put things in their mouths, including dirty hands which may have touched dirt, parasites, and feces, thus increasing exposure to pathogens. This negative impact on younger children is compounded by their weaker body defenses. ${ }^{23}$ As a franchisee explained;

The children who were sick . . . because they are eating the soil while they are sitting here. I think there is a change because now the children are clean and they are enjoying because all the time they come here. They make it like a field [to play] that is not dirty now. I wake up in the morning and then I sweep the area so that the children can play. [Before] they were using this area but it was very dirty. Some people were having some papers [on the ground]... I'm protecting the children. Even the person who wants to urinate near here I just tell him no, no, no. Go there if you don't have some money, go opposite there near the trailers. (Franchisee 1)

Sanergy's sanitation practices, including their rigorous FLT cleaning protocol, also reduce exposure to sanitation-related diseases from using the toilet. Sanergy's focus on improving hygiene practices, such as encouraging hand washing (Fig. 2), further reduces the likelihood of exposure. Hands that have been in contact with feces, and not washed, can be a vector for a number of viruses, bacteria, and parasites including diarrhea, which can reduce nutrient absorption levels and also result in protein energy malnutrition. ${ }^{22}$ When asked how an FLT compared to the commercial toilet options available before Sanergy began operations, an FLT customer explained: 
Table 1. Changes in well-being of children by age and stakeholder role

\begin{tabular}{|c|c|c|c|}
\hline & Children of franchisees & Children of customers & Children of nonusers \\
\hline $\begin{array}{l}\text { Capability } \\
\text { well-being }\end{array}$ & $\begin{array}{l}\text { + Improved health due to: } \\
\text { - Cleaner local environment from less open } \\
\text { defecation }^{a} \\
\text { - Better personal hygiene from improved } \\
\text { sanitation practices }{ }^{b} \\
\text { - Better family and community hygiene from } \\
\text { improved sanitation practices } \\
\text { - Cleaner water supply from waste } \\
\text { management system } \\
\text { Note: Children of franchisees experience most } \\
\text { substantial capability well-being benefits }\end{array}$ & $\begin{array}{l}\text { + Improved health due to: } \\
\text { - Cleaner local } \\
\text { environment from less } \\
\text { open defecation }{ }^{a} \\
\text { - Better personal hygiene } \\
\text { from improved sanitation } \\
\text { practices } \\
\text { - Better family and } \\
\text { community hygiene from } \\
\text { improved sanitation } \\
\text { practices } \\
\text { Cleaner water supply } \\
\text { from waste management } \\
\text { system }\end{array}$ & $\begin{array}{l}\text { + Improved health due to: } \\
\text { - } \text { Cleaner local } \\
\text { environment from less } \\
\text { open defecation }{ }^{a} \\
\text { - Better community } \\
\text { hygiene from improved } \\
\text { sanitation practices } \\
\text { - Cleaner water supply } \\
\text { from waste management } \\
\text { system } \\
\text { Note: Children of nonusers } \\
\text { experience least substantial } \\
\text { capability well-being benefits }\end{array}$ \\
\hline $\begin{array}{l}\text { Economic } \\
\text { well-being }\end{array}$ & $\begin{array}{l}\text { - Decreased income in short term due to: } \\
\text { - Loan repayment }{ }^{a} \\
\text { - Decreased financial reserves in short term (and } \\
\text { perhaps longer) due to: } \\
\text { - Investment of savings in FLT } \\
\text { + Increased income in long term due to: } \\
\text { - Income from FLT exceeding alternative } \\
\text { livelihood earnings and/or cost associated } \\
\text { with owning and operating an FLT } \\
\text { - Savings from no longer needing to pay for } \\
\quad \text { sanitation facilities and reduced medical } \\
\quad \text { expenses } \\
\text { - Less time away from jobs due to improved } \\
\text { health } \\
\text { Note: Children of franchisees experience most } \\
\text { substantial negative short-term and the most } \\
\text { substantial positive long-term impacts to } \\
\text { economic well-being }\end{array}$ & $\begin{array}{l}\text { - Decreased income in long } \\
\text { term due to: } \\
\text { - Paying for FLT use } \\
\text { (change in income based } \\
\text { on level of prior use and } \\
\text { cost of existing options) }^{a} \\
+ \text { Increased income in long } \\
\text { term due to: } \\
\text { - Savings from reduced } \\
\text { medical expenses } \\
\text { - Less time away from jobs } \\
\text { due to improved health }\end{array}$ & $\begin{array}{l}\text { + Increased income in long } \\
\text { term due to: } \\
\text { - Savings from reduced } \\
\text { medical expenses } \\
\text { - Less time away from jobs } \\
\text { due to improved health } \\
\text { Note: Children of nonusers } \\
\text { experience least substantial } \\
\text { negative and positive } \\
\text { economic well-being benefits }\end{array}$ \\
\hline $\begin{array}{l}\text { Relationship } \\
\text { well-being }\end{array}$ & $\begin{array}{l}\text { + Improved social relations due to: } \\
\text { - Increased access to new resources and social } \\
\text { networks } \\
\text { + Improved family relations due to: } \\
\text { - Increased amount of time available to spend } \\
\quad \text { with children }{ }^{a}\end{array}$ & & \\
\hline
\end{tabular}

${ }^{a}$ These influences are larger on children $0-3$ years old.

${ }^{b}$ These influences are larger for children $3-5$ years old.

Compared to the other toilets, the Fresh Life toilet is clean. When I used to go to the other toilets I had the risk of being infected with diseases and being contaminated with dirty water. The Fresh Life toilets are very clean so I am not afraid of anything using the toilet... the diseases which were affecting children here like cholera and diarrhea nowadays the cases are not rampant, they are reduced since the toilet was brought here. (Customer 4)

Another customer offered this comparison:

He [my son] didn't like the [commercial] toilet. The walls of the other toilets are dirty so when my son was there he could get hold of the dirt on the walls on his hands and he'd fall sick as he did not wash his hands. (Customer 5)

A franchisee, in explaining Sanergy's emphasis on hand washing, noted:

There is a change because when they [my children] come here they have to remember to wash their hands so they have to be clean as compared to before. They are less sick, they don't have to spend a lot of time going to the hospital so they have to be in school most of the time. (Franchisee 4) 
Children 3-5 years old can experience improved health outcomes from using FLTs due to reduced exposure to sanitation-related diseases such as diarrhea and cholera, and the flies that spread diseases and parasites. The effect varies depending on the cleanliness of the type of sanitation solution a child used before the FLT, as well as their personal hygiene practices. As one clinic worker explained:

You know how children are naughty, they will want to touch one thing, touch the other, put it in their mouths. But you see now, here the toilet number one is clean, number two they contain [the waste]. If it's the urine, it goes directly where it's supposed to be; if it's the feces, it goes directly where it's supposed to be. So you will not get such kind of stuff on the floor of the toilet; so this prevents again children getting infections. (External Organization - Clinic)

Comparing prior toilet options to an FLT, a headmaster of a school noted:

Flies are always coming because of that hole [in the non FLT] but you find [at] your [FLT] toilet you don't find this kind of thing. Those flies are always associated with some kind of diseases ... diarrhea, cholera. (External Organization - School)

Children of franchisees and users also benefit from their caregivers' and others' use of an FLT through reduced disease transmission. ${ }^{23,25}$ The changes are likely to be more substantial for children of franchisees, as the FLTs are located close to their homes and are free to them and their families. Children of all stakeholder groups benefit from an overall increase in the use of FLTs by other individuals within their community. While their contact with other community members is generally less intensive than with their caregivers, they benefit when these individuals have a lower likelihood of spreading disease. An FLT user who also works as a healthcare provider near the FLT explained:

Since Fresh Life came here we can say we've seen a sign of improvement in terms of health conditions. Before Fresh Life came I remember this place used to be very dirty, everywhere you passed you get some feces [on you], but now since Fresh Life [was] introduced we are much happier because people are using Fresh
Life ... I can really say Fresh Life has really done much ... because of Fresh Life we are not having as much cases of diarrhea and vomiting because the conditions have been improved.

(Customer 2)

Furthermore, other commercial toilets typically dump their waste in the Ngong river that runs through Mukuru (Fig. 3) or in one of the drainage systems within the local community. Sanergy views this waste as an input for creating energy as well as fertilizer, and has implemented a system of daily waste collection (Fig. 5). This results in improved water quality for the community, which can generate health benefits for all young children. ${ }^{27,28}$ Although some individuals purchase water for drinking and cooking, others use the Ngong river for drinking and cooking as well as other household-related activities. A customer and a franchisee, respectively, highlighted the improved drainage:

Before the [FLT] toilet was brought here that drainage stream that was there used to be filled with paper that had waste but now it is cleaner. (Customer 4)

The flying toilet cases have reduced. Drainage is flowing, is not stagnate. (Franchisee 3)

\section{Economic well-being}

Our findings indicate that Sanergy's approach also can have important economic well-being impacts, both positive and negative, on children 5 years old and younger. These impacts vary depending on the time frame of the impact and the caregiver's role in the business model. The most substantial negative short-term impacts are on the children of franchisees. The franchisees must purchase an FLT. To do so, they take out a loan, draw down their existing assets, or use a combination of both. Sanergy estimates that it takes about 7 months for a franchisee to repay a loan. Until that time, children in these families can face a fairly substantial change in disposable income, especially if the loan repayment exceeds the FLT-generated revenues. A franchisee explained to us the loan and associated costs she faced from starting with an FLT and how that affected her spending:

I paid 70,000 shillings [for two Fresh Life toilets] ... I had some money I used to start with the first toilet but for the second one I had to borrow from microfinance. Per month, I pay 
4,000 for the microfinance. I borrowed 30,000. I am nearly finished [paying the loan]... I make about 300 shilling from the toilets daily. I use 100 shillings for daily uses like buying food and then save 200 shillings [to put toward the loans]... My income has gone up since I stopped selling vegetables [and started with Fresh Life but] I have less money now [because of paying back the loan] so I have to spend less on buying food. (Franchisee 3 )

Furthermore, until the investment in the FLT is recovered, families like the franchisee above may have a lower level of financial reserves available. As such, these families will be less able to respond to unexpected shocks, such as loss of a job, substantial medical bills, or other unexpected major household expenses.

Also, the franchisee must remain close to the FLT, meaning that the opportunity to generate income from alternative livelihood activities can be constrained. Some franchisees instead chose to hire someone else to manage their FLTs, which also influences their daily cash flow. Others have an elderly family member, such as a grandmother, help run the FLT. Potential income declines are offset somewhat as a result of the family no longer needing to pay to use commercial facilities. One franchisee explained the economic implications of changing occupations to become an FLT operator:

I have left selling the clothes now [since getting the FLT] ... The first month you can't know if it [income] is improving but I can see now there is improvement... Let me say it is about 4,500 [shilling for one month of operating the FLT] ... Because I am not going on bus there is no transport, I just wake up and come here.

(Franchisee 1)

The situation for franchisees' children changes if the FLT is cash-flow positive, especially once the loan is repaid and the investment is recovered. There is, however, no certainty in that outcome. The economic benefits from a successful business may take longer than expected to occur, or may never materialize. When the business becomes cash-flow positive, the FLT can generate a steady source of disposable income for the family, and more financial resources could become available for children. With an income of, for example, U.S. $\$ 2 /$ day, franchisees can earn more than $\$ 700 /$ year from their FLT. As the same franchisee goes on to mention:

... [Before the FLT] my granddaughter would go to school without taking tea... [now] she can go and buy bread and buy something and now I've got money. But the other time she was going to school without the tea, no money, no cash, no money for buying some milk. So even my granddaughter is enjoying all the time she comes here while I am sitting here and says give me money for buying bread and I just go in my pocket. Now I'm rich... It is a daily income now... But the last year [before the FLT], I had no money because there is no daily income... But this time there is always something in my pocket. (Franchisee 1)

Other potential longer-term economic benefits include decreased family medical expenses and fewer sick days for the family's income-earners. These savings can be substantial, as daily local wages for construction work, for example, averages about 300 KES (U.S. \$3.5). Overall, the children of franchisees face the greatest negative economic wellbeing challenges in the short term, but are also likely to experience the most substantial positive economic changes in the long term.

The introduction of Sanergy's FLTs can also have negative short-term impacts on the economic wellbeing of the children of customers. This impact varies depending on how often these families previously used other commercial toilets in the area and how they paid per use. As one customer explained:

I pay 3 shillings [per usage to use FLT] ... [before] I used the commercial toilets down there [which were] 2 shillings ... the [FLT] toilets are clean and high standards compared to the other toilets. (Customer 4)

Any change, therefore, is mostly due to new patterns of usage and changes in price per use. For families who previously did not use commercial toilets as well as those that used them less often or paid less per use, the money to pay for access to FLTs is diverted away from other needs. While there are likely some long-term economic benefits from improved health, such as decreased medical expenses and fewer sick days, these families must make tradeoffs in the short term if they are to use the FLTs. The 
economic impact associated with using the FLTs was also noted by nonusers:

It is expensive here [at the Fresh Life toilet] compared to the other place [commercial toilets] ... if I do not have money then I can use it [the bush] ... Mostly it is money [why people don't use the toilet]. (Nonuser 1)

[The children and I] use commercial toilets which charge 1 shilling... The price is cheaper compared to this one [the Fresh Life toilet]... Even if the child doesn't have money they [the commercial toilets] allow them to go in. (Nonuser 5)

For both franchisees and customers, the impacts of changes in economic well-being are likely to be more substantial on children aged $0-3$ years. These children are more vulnerable to changes in financial resources, especially when it affects their nutrition. ${ }^{19}$ Less disposable income can mean less money for food. A nutritional deficit can have longterm implications for a child's health, as well as their school performance and other achievement-related outcomes. ${ }^{19,20}$

The children of nonusers face more modest changes in their economic well-being. As nonusers, there is no change in their short-term financial situation, although they may still prefer to use an FLT if they could afford it. One nonuser explained:

I would use the FLT if there was no charge. I don't like it [the pit latrine] because it is dirty because everyone uses it and they don't clean it. (Nonuser 3)

Over the longer term, if the overall community becomes healthier, nonusers, like the other stakeholders, can still benefit economically from lower family medical expenses and fewer work days lost to sanitation-related illnesses among their caregivers.

\section{Relationship well-being}

Children of franchisees realize impacts from changes in relationship well-being. These include the benefits associated with their caregivers' increased connections to new resources and social networks. As an FLT franchisee, the caregivers of these children can gain access to microcredit, enhancing their financial inclusion. They also expand their networks through interactions with Sanergy staff and other community members who use the FLT. These new resources and relationships can benefit children by providing their caregivers with greater flexibility and more time to pursue future opportunities and respond to any challenges. ${ }^{21}$ As two franchisees explained:

It is now that I am operating the Fresh Life toilet that I associate with more people compared to when I was selling vegetables. (Franchisee 3)

The members of Fresh Life are happy all the time. The members of Fresh Life come to visit me all the time; even the people who are collecting the waste, they are very happy. So I have seen something very good here... I was the first one trained... Now I become an advisor to the other people. I've told them about the Fresh Life toilet. They are asking me [questions] ... I think they learn there are good relations [with Sanergy]. (Franchisee 1)

A Sanergy employee noted that the franchisees are now able to participate in new activities and access new networks and resources:

We have heard from women, especially that they are better able to... participate in women's groups or self-empowerment groups or other things that they can have direct benefits from because they have more time because they are not taking care of their [sick] children...hours spent because of healthrelated issues. (Sanergy employee 4)

Furthermore, franchisees, unless they hire someone, must stay near their FLTs to service their customers. As the FLTs are generally located near their homes, these caregivers are now able to spend more time with their children. Previously, many had to leave for work early in the morning and return late at night. Parental stimulation in the first 3 years of life is particularly important. Children who spend these years in less supportive environments can face cognitive, social, and behavioral delays, and experience lower productivity levels as adults. ${ }^{21}$ As a Sanergy employee noted:

Franchisees have their toilets close to their home, like it is now right next door... The time with the family is enhanced, like for example some of them previous business they 
had to leave very early in the morning, come late. That was taking away from their family but now they have a job that is right at their doorstep. (Sanergy employee 5)

\section{Discussion}

Enterprise-led interventions incorporating convergent innovation offer an alternative approach to providing a public good, such as urbanbased sanitation. ${ }^{8}$ In linking profits to poverty reduction and combining top-down management with bottom-up ownership, these enterprises offer the promise of sustainable and scalable poverty alleviation. ${ }^{40}$ Achieving this promise, however, requires having a robust understanding of who within the BoP is affected and how. ${ }^{9}$

Earlier research on evaluating the effectiveness of sanitation interventions generally focused on health outcomes. ${ }^{3}$ Our findings indicate that this orientation may be overly myopic. Indeed, our study demonstrates the value of adopting a multidimensional view of poverty, even if the intervention is designed to target a specific poverty-alleviation outcome.

Sanergy's approach can affect the capability wellbeing of young children through changes in health outcomes. The BoP enterprise's business model, however, can also affect other poverty dimensions. Children of franchisees, for instance, can face changes in both their economic and relationship well-being. Franchisees must invest in acquiring an FLT, which has negative implications - at least in the short term-for cash flow and economic reserves available. ${ }^{c}$ These changes can become more permanent if the franchisee does not create a viable business from their FLT. Changes in relationship well-being can also occur if social networks expand, resulting in access to new opportunities, connections, and resources.

As enterprise-led business models typically involve new and varying roles for different community members, careful and holistic assessments of their impacts across stakeholders are particularly crucial. ${ }^{9}$ Our analysis of Sanergy offers support for

\footnotetext{
${ }^{c}$ Since our data collection concluded Sanergy has begun working with Kiva (www.kiva.org) to offer franchisees a $0 \%$ interest loan with a $25-30 \%$ down payment.
}

this perspective. Children of all BoP stakeholders, including nonusers, can benefit from more FLTs and more FLT users in the long term. Yet these impacts are not evenly distributed.

Our results demonstrate that utilizing a multistakeholder perspective to assess impact can reveal important variation across groups. While FLTs are communal toilets designed to serve the broader community, Sanergy's approach generates the greatest health benefits for children in inverse proportion to the size of the different groups. As presented in Table 1, children of franchisees, who are the smallest group, benefit the most due to free use and close proximity to FLTs. These children can also receive the most substantial improvements in long-term economic and relationship well-being. The children of nonusers, by far the largest group, receive the most limited health benefits, but receive these at no economic cost. We also find that the magnitude of these impacts vary within these groups. The health benefits, for example, of less open defecation may benefit children from $0-3$ years old the most, while improved sanitation practices can have a greater impact on children from 3-5 years old.

For practitioners, including those interested in promoting the distribution of a public good, these impact assessment findings provide insights into how to improve an intervention's value proposition. Sanergy's current business model produces, for example, financial burdens on users that can negatively affect the well-being of their children. These impacts on economic well-being may also be an important barrier that prevents more nonusers from converting to users. Sanergy and its partners might therefore want to investigate options for donors or other external funders to invest in providing vouchersor other mechanisms that minimize the financial impact - to children of certain existing customers as well as targeted nonusers. ${ }^{2}$ These investments could encourage more use of FLTs, reduce the negative impacts on users, and potentially improve franchisees' ability to create a financially viable business.

This latter point is particularly relevant in enhancing the effectiveness of an enterprise-led intervention. If the individual sellers, in this case the franchisees, do not realize an overall improvement in their well-being, they may discontinue their involvement with the BoP enterprise. Sanitation is a public good and if they withdraw, all the stakeholders in the community can suffer. Thus, although 
they are the smallest group in terms of size, franchisee success is a lynchpin for enterprise-led sustainability and scalability. Therefore, Sanergy and its partners might also want to explore options to reduce the negative financial burdens on franchisees, including providing access to lower-cost financing or subsidizing the cost to purchase an FLT. $^{2}$ With reduced upfront investment and risk, franchisees might also reduce the price per FLT use. This therefore could be an alternative, and less costly, option to increasing the use of FLTs by the community.

Although limited to a single case study, these results also suggest that the evaluation of the effectiveness of any sanitation-based approach, be it an enterprise-led, government-led, or community-led intervention, can benefit from incorporating a multidimensional perspective of poverty. Our qualitative methodology was designed to generate a rich understanding of multiple dimensions of poverty across a diverse set of local stakeholders. Future researchers may want to conduct survey-based studies to better quantify specific changes in well-being among stakeholders or compare impacts across different sanitation models. Moving forward, additional studies of different interventions will enable a more robust comparison of their effectiveness and impact across different stakeholders.

In summary, enterprise-led interventions that incorporate convergent innovation offer an alternative approach to tackling major challenges in providing public goods to the BoP, such as inadequate sanitation in an urban setting. As our study of one of these BoP enterprises demonstrates, a multidimensional poverty alleviation assessment can contribute a richer and more holistic understanding of the effectiveness of this approach.

\section{Acknowledgments}

This research was supported by the Bernard van Leer Foundation. The authors' views expressed in this article do not necessarily reflect the views of the Bernard van Leer Foundation. The authors thank Thomas Buchmueller, Prashant Yadav, and the special issue editors and reviewers for their helpful comments and suggestions.

\section{Conflicts of interest}

The authors declare no conflicts of interest.

\section{Supporting Information}

Additional supporting information may be found in the online version of this article.

Table S1. Additional data on Sanergy's impacts on well-being

\section{References}

1. UNDP. 2006. Human Development Report 2006. Beyond Scarcity: Power, Poverty and the Global Water Crisis. New York: UNDP.

2. Evans, B. 2005. Securing Sanitation: The Compelling Case to Address the Crisis. Stockholm: Stockholm International Water Institute.

3. Duflo, E., S. Galiani \& M. Mobarak. 2012. Improving Access to Urban Services for the Poor: Open Issues and a Framework for a Future Research Agenda. Abdul Latif Jameel Poverty Action Lab.

4. Growing Inclusive Markets Initiative. 2008. Creating Value for All: Strategies for Doing Business with the Poor. New York: UNDP.

5. Commission on the Private Sector and Development. 2006. Unleashing Entrepreneurship: Making Business Work for the Poor. New York: UNDP.

6. World Bank. 2001. World Development Report 2000/2001: Attacking Poverty: v. New York: Oxford University Press.

7. Hammond, A.L. et al. 2007. The Next Four Billion: Market Size and Business Strategy at the Base of the Pyramid. Washington, DC: World Resources Institute and International Finance Corporation.

8. Dubé, L. 2012. Paths of convergence for agriculture, health and wealth. Proc. Natl. Acad. Sci. USA 109: 12294-12301.

9. London, T. 2009. Making better investments at the base of the pyramid. Harv. Bus. Rev. 87: 106-113.

10. Ansari, S., K. Munir \& T. Gregg. 2012. Impact at the 'bottom of the pyramid': The role of social capital in capability development and community empowerment. J. Manage Stud. 49: 813-842.

11. Sheuya, S.A. 2008. Improving the health and lives of people living in slums. Ann. N.Y. Acad. Sci. 1136: 298-306.

12. Sen, A. 1999. Development as Freedom. New York: Anchor Books.

13. WHO. 2013. Sanitation. http://www.who.int/topics/sanita tion/en/.

14. Spears, D. \& S. Lamba. 2013. Effects of Early-Life Exposure to Sanitation on Childhood Cognitive Skills: Evidence from India's Total Sanitation Campaign. September 20, 2013. http://riceinstitute.org/wordpress/wp-content/uploads/ downloads/2013/10/Spears-and-Lamba-2013.pdf.

15. WHO. 2013. 10 facts on sanitation. http://www. who.int/features/factfiles/sanitation/facts/en/indexl.html.

16. Fewtrell, L. et al. 2005. Water, sanitation, and hygiene interventions to reduce diarrhoea in less developed countries: a systematic review and meta-analysis. Lancet Infect. Dis. 5: $42-52$. 
17. WHO. 2004. Facts and figures: water, sanitation and hygiene links to health. http://www.who. int/water'sanitation health/publications/factsfigures04/en/.

18. Spears, D. 2013. How Much International Variation in Child Height Can Sanitation Explain? In Policy Research Working Paper. Washington, DC: The World Bank.

19. Grantham-McGregor, S. et al. 2007. Developmental potential in the first 5 years for children in developing countries. Lancet 369: 60-70.

20. Brooks-Gunn, J. \& G.J. Duncan. 1997. The effects of poverty on children. Future Child. 7: 55-71.

21. WHO. 2009. Early child development. Fact sheet Number 332. http://www.who.int/mediacentre/fact sheets/fs332/en/index.html.

22. UNICEF \& WHO. 2009. Diarrhoea: Why Children Are Still Dying and What Can Be Done? New York: UNICEF. http://www.unicef.org/media/files/Final_Diarrhoea_ Report_October_2009_final.pdf.

23. WHO. 2002. Children's Health and Environment: A Review of Evidence. European Environment Agency and World Health Organization, Regional Office for Europe. Copenhagen.

24. Nandy, S. \& D. Gordon. 2009. Children living in squalor: Shelter, water and sanitation deprivations in developing countries. Child Youth Environ. 19: 202-228.

25. Spears, D. 2012. Effects of Rural Sanitation on Infant Mortality and Human Capital: Evidence from India's Total Sanitation Campaign. July 3, 2012. http://riceinstitute.org/ wordpress/wp-content/uploads/downloads/2012/07/ tsc-summer-2012.pdf.

26. Esrey, S.A. \& J.-P. Habicht. 1986. Epidemiological evidence for health benefits from improved water and sanitation in developing countries. Epidemiol. Rev. 8: 117-128.

27. Amnesty International. 2009. Kenya - The Unseen Majority: Nairobi's Two Million Slum-Dwellers: 1-44. London: Amnesty International Publications.

28. World Bank Development Marketplace. 2005. Credit for safe collection of used oil. http://wbi. worldbank.org/developmentmarketplace/idea/creditsafe-collection-used-oil.

29. Kar, K. 2012. Why not basics for all? Scopes and challenges of community-led total sanitation. IDS Bull. 43: 93-96.

30. United Nations. 2010. The Millennium Development Goals Report. New York: The United Nations Department of Economic and Social Affairs.

31. WHO \& UNICEF. 2012. Progress on Drinking Water and Sanitation: 1-58. New York: WHO.

32. United Nations. 2008. World Urbanization Prospects: The 2007 Revision-Highlights. New York: Department of Economic and Social Affairs, Population Division.

33. WaterAid. 2007. Water, Environmental Sanitation and Hygiene Programme for Urban Poor. Kupondole: WaterAid, UNHabitat.

34. Nicol, A., L. Mehta \& J. Allouche. 2012. Introduction: 'Some for all rather than more for some'? Contested pathways and politics since the 1990 New Delhi statement. IDS Bull. 43: 1-9.
35. Mehta, L. \& S. Movik. 2011. Shit Matters: The Potential of Community-led Total Sanitation. Rugby: Practical Action.

36. Kar, K. \& R. Chambers. 2008. Handbook on Communityled Total Sanitation. Brighton and London: IDS and Plan International.

37. Prahalad, C.K. \& S.L. Hart. 2002. The fortune at the bottom of the pyramid. Strategy+Business. 26: 2-14.

38. Prahalad, C.K. 2005. The Fortune at the Bottom of the Pyramid: Eradicating Poverty Through Profits. Upper Saddle River, NJ: Wharton School Publishing.

39. London, T. \& S.L. Hart. 2004. Reinventing strategies for emerging markets: beyond the transnational model. J. Int. Bus. Stud. 35: 350-370.

40. London, T., R. Anupindi \& S. Sheth. 2010. Creating mutual value: lessons learned from ventures serving base of the pyramid producers. J. Bus. Res. 63: 582-594.

41. London, T. \& S. Hart. 2011. Next Generation Business Strategies for the Base of the Pyramid: New Approaches for Building Mutual Value. Upper Saddle River, NJ: FT Press.

42. Simanis, E., S. Hart \& D. Duke. 2008. The base of the pyramid protocol: Beyond "basic needs" business strategies. Innovations 3: 57-84.

43. Riddell, R.C. 2007. Does Foreign Aid Really Work?. Oxford: Oxford Press.

44. Easterly, W. 2006. The White Man's Burden: Why the West's Efforts to Aid the Rest have Done so Much Ill and so Little Good. New York: Penguin Press.

45. Collins, D. et al. 2009. Portfolios of the Poor: How the World's Poor Live on \$2 a Day. Princeton, NJ: Princeton University Press.

46. Leonard, H.B. 2007. When is doing business with the poor good - for the poor? A household and national income accounting approach. In Business Solutions for the Global Poor: Creating Social and Economic Value. V.K. Rangan et al., Eds.: 362-373. San Francisco, CA: Jossey-Bass.

47. The Foundation Center. 2012. Tools and Resources for Assessing Social Impact, Vol. 2012. New York. http://trasi.foundationcenter.org/record.php?SN=151 [27 Dec 2012].

48. World Business Council for Sustainable Development. 2013. Measuring socio-economic impact: a guide for business. The World Business Council for Sustainable Development ConchesGeneva (forthcoming).

49. The Willam Davidson Institute. 2012. Base of the Pyramid Impact Assessment Framework, Vol. 2012. Ann Arbor.

50. The World Bank. 2001. World Development Report 2000/2001: Attacking Poverty. Oxford: Oxford University Press.

51. Kakwani, N. \& J. Silber. 2008. Introduction: multidimensional poverty analysis: conceptual issues, empirical illustrations and policy implications. World Dev. 36: 987-991.

52. Hulme, D. \& A. Shepherd. 2003. Conceptualizing chronic poverty. World Dev. 31: 403-423.

53. Chambers, R. 1997. Whose Reality Counts?: Putting the First Last. London: ITDG Publishing.

54. Narayan, D. et al. 2000. Voices of the Poor: Can Anyone Hear Us? Oxford: Oxford University Press. 
55. Sen, A. 2000. Social Exclusion: Concept, Application, and Scrutiny. In Social Development Papers No. 1. Asian Development Bank. Office of Environment and Social Development.

56. Chambers, R. 1983. Rural Development: Putting the Last First. Harlow, England: Prentice Hall.

57. African Population and Health Research Center. 2012. The Nairobi urban health and demographic surveillance system. http://www.aphrc.org/insidepage/?articleid $=470$.
58. Sanergy. 2013. By the Numbers. http://saner.gy/ourimpact/by-the-numbers. Accessed May 2013.

59. Eisenhardt, K.M. 1989. Building theories from case study research. Acad. Manage. Rev. 14: 532-550.

60. Yin, R.K. 1984. Case Study Research. Beverly Hills, CA: Sage Publications.

61. Miles, M. \& A.M. Huberman. 1994. Qualitative Data Analysis: An Expanded Sourcebook. 2nd edition. Thousand Oaks, CA: SAGE Publications, Inc. 